\title{
ANÁLISE DOS IMPACTOS DOS CPCS DA PRIMEIRA FASE DE TRANSIÇÃO PARA O IFRS NO BRASIL: UM EXAME DOS AJUSTES AOS RESULTADOS NAS DFPS DE 2008
}

\author{
ANALYSIS OF IMPACTS OF EACH NEW NORM FROM THE FIRST TRANSITION PHASE \\ TO THE IFRS IN BRASIL: AN EXAMINATION OF THE ADJUSTMENTS AND THE RESULTS \\ IN FINANCIAL REPORTS IN 2008
}

\author{
Edilene Santana Santos ${ }^{a}$ \\ ${ }^{a}$ Doutora em Controladoria e Contabilidade pela Universidade de São Paulo \\ Professora da FGV - Escola de Administração de São Paulo EAESP \\ São Paulo/SP, Brasil \\ E-mail: edilene.santos@fgv.br
}

\section{Resumo}

No contexto da convergência da contabilidade brasileira para o padrão internacional, a partir da Lei 11.638/07, este trabalho tem como objetivo mensurar e analisar o impacto de cada mudança normativa (CPC) da primeira fase de transição para o International Financial Reporting Standard (IFRS) nos resultados das empresas. Foram examinadas as 175 empresas que apresentaram a tabela de reconciliação dos efeitos da Lei nas Notas Explicativas das Demonstrações Financeiras Padronizadas de 2008. O impacto de cada CPC foi mensurado pelo inverso do "Índice de Comparabilidade Parcial" de Weetman et al. (1998), dentro do quadro teórico de "valores contábeis" e do "Índice de Conservadorismo" de Gray (1980, 1988). Os impactos destacados foram: a exclusão dos custos de transação e prêmios na emissão de títulos do resultado, que em média triplicou o lucro das empresas que reportaram esse ajuste em 2007; e o impairment de ativos, que gerou queda média de $260 \%$ no lucro das empresas que o registraram em 2008.

Palavras-chave: CPCs, IFRS, Índice de Comparabilidade, Lei 11.638.

\begin{abstract}
In regard to the Brazilian international accounting convergence to the international standards, according to the Law 11.638/07, this work aims to measure and analyze the impact on the companies' results of each new norm proceeded from the first transition phase to the IFRS (International Financial Reporting Standard). 175 public companies that published the reconciliation table of the effects of the new Law on the Explanatory Notes of their 2008 Financial Reports were examined. The impact of each norm was measured by the inverse of Weetman et al. (1998)'s "Partial Comparability Index", according to Gray's (1980, 1988) "accounting values" and "Index of Conservatism". The most proeminent impacts were: the exclusion of transaction costs and premiums for the bonds issued, which in average tripled the profits of the companies that reported this adjustment in 2007; and the impairment of assets, wich led to a $260 \%$ average decrease in the profits of the companiesreporting it in 2008.
\end{abstract}

Keywords: ICPCs, IFRS, Index of Comparability, Law 11.638 


\section{INTRODUÇÃ̃o}

O processo de convergência da contabilidade brasileira para o International Financial Reporting Standard (IFRS), a partir da Lei 11.638/07, vem atraindo a atenção de reguladores, pesquisadores, agentes do mercado e imprensa especializada, com grande expectativa, tanto sobre as alterações normativas em si, como sobre seus efeitos nos relatórios financeiros das empresas, e até no perfil dos profissionais envolvidos (NIERO, 2008; NIERO et al, 2009; LIPPI, 2009; TORRES, 2009; entre outros).

Essa expectativa foi aumentada pelo fato de a Lei ter sido publicada no último dia útil de 2007, com vigência já a partir de 2008, levando a Comissão de Valores Mobiliários (CVM) a determinar a adoção do IFRS no Brasil em duas etapas: a primeira, com adoção inicial da Lei (CPCs 1 a 14) em 2008, e a segunda, com adoção completa do full IFRS a partir de 2010.

Para permitir a comparabilidade dos resultados apurados seguindo as regras antigas com os produzidos sob as novas normas, a CVM determinou que, na adoção inicial da Lei, as empresas evidenciassem em Nota Explicativa a conciliação do Lucro Líquido (LL) e do Patrimônio Líquido (PL), apurados conforme os dois conjuntos normativos (CPC 13). Assim, a partir das primeiras publicações de relatórios sob as novas normas em 2009, abre-se a oportunidade para se investigar o impacto dessa mudança nos resultados reportados pelas empresas.

Dentre os poucos estudos sobre o assunto até o momento, Santos (2009) identifica os impactos das normas da primeira fase de transição para o IFRS no resultado das empresas listadas na Bovespa. Entretanto, esse estudo (assim como o de Grecco et al., 2009), é focado no impacto das mudanças como um todo, deixando em aberto uma análise detalhada dos efeitos específicos de cada nova norma sobre os resultados das empresas. Por outro lado, o próprio estudo de Santos (2009) aponta que, embora tenha sido apurado um impacto total de aproximadamente $+8 \%$ no lucro de 2007 e de $-7 \%$ em 2008, vários ajustes individuais geraram impactos bem mais expressivos, o que ressalta a relevância de uma análise mais aprofundada do impacto de cada ajuste, objeto da presente investigação.

Nesse contexto, o problema desta pesquisa pode ser assim definido: qual o impacto de cada nova norma (CPCs 1 a 14) da primeira fase de transição para o IFRS nos resultados das empresas? Mais especificamente, o quanto cada CPC impactou o Lucro e o PL das empresas brasileiras? Quais normas mais impactaram os resultados e quais foram as mais frequentes entre as empresas?

Este trabalho tem como objetivo mensurar e analisar o impacto de cada nova norma da primeira fase de transição para o IFRS nos resultados das empresas listadas na Bovespa. Ao identificar esses impactos, este trabalho pretende contribuir para o melhor entendimento dos efeitos da Lei, em especial para fins de análise financeira de empresas e setores mais afetados pelas novas normas.

Do ponto de vista metodológico, este estudo é empírico-analítico descritivo, aplicando o inverso do Índice de Comparabilidade Parcial (ICP) de Weetman et al. (1998) para mensurar o impacto de cada novo CPC nos resultados das empresas. São examinadas as empresas que apresentaram a tabela de reconciliação dos efeitos das novas normas no LL e/ou PL nas Notas Explicativas das Demonstrações Financeiras Padronizadas (DFPs) de 2008. 


\section{REVISÃO DA LITERATURA}

\subsection{Estudos anteriores}

A transformação profunda da prática contábil brasileira ora em curso no processo de transição para o padrão internacional traz consigo mudanças que também ocorreram em outros países, evidenciando diferenças de posturas culturais, institucionais e profissionais dos respectivos sistemas contábeis, que vêm sendo estudadas na literatura há décadas.

Assim, Gray (1980, 1988), Saudagaran (2001), Ding et al. (2005) e Radebaugh et al. (2006), entre outros, identificam razões culturais e institucionais de tais diferenças, contrapondo os países de influência anglo-americana, de direito consuetudinário (common law), aos países de influência eurocontinental (Alemanha, Bélgica, Espanha, França, Itália, Japão e países da América do Sul), de direito formalista (code law). Gray (1988) sintetiza essas diferenças, classificando os sistemas nacionais pela gradação entre quatro "valores contábeis" (accounting values): julgamento pelo profissional contábil versus controle governamental e estatutário; flexibilidade versus uniformidade diante de circunstâncias específicas; grau de transparência versus segredo das informações; e conservadorismo versus otimismo na mensuração (ver também Niyama, 2005).

A mudança de valores requerida pela convergência para o IFRS é considerada por Iudíciubus et al. (2009, p.66) como uma "nova filosofia contábil” no Brasil, caracterizada pela introdução da “(...) primazia da essência sobre a forma, normas contábeis orientadas por princípios, e não por enorme conjunto de regras detalhadas e, como consequência (...), pela necessidade cada vez maior do julgamento por parte do profissional da Contabilidade (...)".

$\mathrm{Na}$ busca por instrumentos aptos a quantificar os efeitos de diferenças culturais sobre os números contábeis, Gray (1980) propôs o "Índice de Conservadorismo", que mede o quanto lucros maiores (caracterizando otimismo, observado na Inglaterra) ou menores (conservadorismo, observado na França e Alemanha) eram demonstrados pelos respectivos sistemas contábeis desses países, num primeiro momento, comparativamente ao padrão inicial europeu e, posteriormente, aos US GAAP. Weetman et al. (1998) o renomearam para "Índice de Comparabilidade" total (IC, referente ao todo do resultado) ou parcial (ICP, referente a cada ajuste por diferença normativa específica). Conforme esses autores, nas equações (1) e (1A), um IC/ICP menor que 1 denota conservadorismo na mensuração (lucros/ajustes locais menores em relação aos US GAAP) e, vice-versa, um IC/ICP maior que 1 indica otimismo (lucros/ajustes locais superiores aos apurados pelos US GAAP).

$$
I C=1-\left[\frac{R_{A}-R_{D}}{\left|R_{A}\right|}\right] \text { (1) } \quad I C P=1-\left[\frac{\text { Ajuste Parcial }}{\left|R_{A}\right|}\right]
$$

Onde:

$R A=$ lucros (ou retornos) ajustados para os US GAAP
$R D=$ lucros (ou retornos) apurados conforme práticas locais de cada país

Ajuste Parcial = cada ajuste por diferença normativa especifica efetuado para reconciliar os lucros (ou retornos) apurados conforme práticas locais de cada país com os US GAAP 
Usando essa metodologia, Beckman et al. (2007) identificam a tendência da contabilidade tradicional alemã em expressar lucros e PL menores em relação tanto ao IFRS como aos US GAAP, principalmente em decorrência da reversão de provisões e de accruals, e da reversão de impairment de ativos (assets write downs).

Cordazzo (2008) aplica a mesma metodologia na Itália, confirmando resultados menores pela norma italiana em relação ao IFRS, e destacando os ajustes business combinations, provisões, instrumentos financeiros, e ativos intangíveis, impactando lucro e PL, e tributos e imobilizado, impactando significativamente apenas o PL.

O’Connell e Sullivan (2008) comparam as duplas demonstrações, pela norma local e pelo IFRS, de empresas de países de tradição eurocontinental (Alemanha, Bélgica, Espanha, França, Itália, Holanda e Portugal) que anteciparam a adoção do IFRS, confirmando lucros maiores pela nova norma, principalmente devido ao impacto do tratamento de Business Combinations.

No Brasil, Santos e Cia (2009) aplicaram a metodologia de Gray/Weetman para estimar o impacto da harmonização internacional no lucro das emissoras brasileiras de ADRs na NYSE, tendo como proxy os ajustes BRGAAP/USGAAP, no período 2001-2006. Esse estudo identificou como ajustes mais significativos: correção monetária de 1996-1997, combinação de negócios, instrumentos financeiros e reavaliação de ativos. Além desse estudo, Lemes et al. (2007) investigaram a comparabilidade da contabilidade brasileira com os US GAAP; Doupnik e Riccio (2006) compararam características culturais de profissionais brasileiros e americanos em julgamentos que afetam o resultado, confirmando o conservadorismo brasileiro previsto por Gray (1988); e Santos et al. (2007) chegaram à mesma conclusão, comparando resultados duplamente reportados (em BRGAAP e USGAAP) por emissoras brasileiras de ADRs.

Com o advento da lei 11.638/07, o impacto das normas da primeira fase da transição para o IFRS nos resultados das empresas listadas na Bovespa foi estudado por Santos (2009), com extrato dos resultados publicados em Santos e Calixto (2010). Entretanto, esse estudo, bem como os de Grecco et al. (2009) e de Furutura et al. (2010), são focados no impacto total das novas normas como um todo, deixando em aberto um aprofundamento dos efeitos de cada norma, para o qual a presente investigação pretende contribuir.

\subsection{Mudanças normativas introduzidas na primeira fase de transição para o IFRS}

Conforme já comentado, na regulamentação da Lei 11.638/07, a CVM (2008) optou por introduzir uma transição gradativa para o IFRS no Brasil, em duas fases. Foi emitido um conjunto de normas para a primeira fase, de "adoção inicial" da lei (CPCs 1 a 14) em 2008, ficando para 2010 a fase final, de "integral convergência" para o full IFRS.

Um resumo das principais mudanças normativas com efeito potencial no lucro e/ou PL das empresas, introduzidas na primeira fase de transição para o IFRS é apresentado no Quadro 1 . 
Quadro 1: Principais Mudanças da $1^{\text {a }}$ Fase de Transição para o IFRS com Efeito Potencial no Lucro e/ou Patrimônio Líquido das Empresas

\begin{tabular}{|c|c|c|}
\hline $\begin{array}{c}\text { Categorias de } \\
\text { Ajustes }\end{array}$ & $\begin{array}{l}\text { IASB, CPC } \\
\text { Del. CVM }\end{array}$ & Mudanças com efeito potencial no Lucro e/ou Patrimônio Líquido \\
\hline $\begin{array}{l}\text { Redução de } \\
\text { Ativos ao Valor } \\
\text { Recuperável } \\
\text { (impairment) }\end{array}$ & $\begin{array}{c}\text { IAS } 36 \\
\text { CPC 01 } \\
\text { Del. 527/07 }\end{array}$ & $\begin{array}{l}\text { Institui a exigência de se fazerem testes regulares de impairment para verificar } \\
\text { a necessidade de reduzir o valor contábil dos ativos ao seu valor recuperável, } \\
\text { com reconhecimento da perda no resultado. } \\
\text { Embora essa lógica já estivesse de certa forma prevista, era pouco praticada } \\
\text { entre as empresas. A instituição de testes de impairment anuais para ativos } \\
\text { intangíveis, em especial para o ágio na aquisição de participações em outras } \\
\text { companhias, em substituição à amortização sistemática, pode gerar reduções } \\
\text { bruscas no resultado das empresas em alguns exercícios. }\end{array}$ \\
\hline $\begin{array}{l}\text { Efeitos das } \\
\text { Mudanças nas } \\
\text { Taxas de Câmbio } \\
\text { e Conversão de } \\
\text { Demonstrações } \\
\text { Contábeis }\end{array}$ & $\begin{array}{c}\text { IAS } 21 \\
\text { CPC 02 } \\
\text { Del. } 534 / 08\end{array}$ & $\begin{array}{l}\text { Potencialmente, empresas que utilizavam o dólar como moeda funcional } \\
\text { tenderão a substituí-lo pelo Real, mudando o método de conversão das } \\
\text { demonstrações contábeis, com efeitos no resultado. } \\
\text { As variações cambiais decorrentes da conversão de controladas estrangeiras } \\
\text { eram em geral registradas no resultado em vez de diretamente no patrimônio } \\
\text { líquido na conta Ajustes de Avaliação Patrimonial. }\end{array}$ \\
\hline $\begin{array}{l}\text { Ativo Intangível } \\
\text { (antes Diferido) }\end{array}$ & $\begin{array}{c}\text { IAS } 38 \\
\text { CPC } 04 \\
\text { Del. } 553 / 08\end{array}$ & $\begin{array}{l}\text { Extingue o grupo Ativo Diferido e cria o grupo Ativo Intangível. } \\
\text { Proíbe a capitalização de praticamente todas as despesas antes passíveis } \\
\text { de serem lançadas no Diferido - despesas pré-operacionais, gastos com } \\
\text { reestruturação, pesquisa e desenvolvimento, alguns tipos de gastos com } \\
\text { publicidade epropaganda e treinamento - lançando-as agora contra o resultado. } \\
\text { Cria uma série de exigências para reconhecimento de ativos intangíveis } \\
\text { desenvolvidos internamente. } \\
\text { Saldos anteriores de Ativos Diferidos podem ser baixados integralmente na } \\
\text { data de transição ou continuar a ser amortizados pelo prazo remanescente. }\end{array}$ \\
\hline $\begin{array}{l}\text { Operações de } \\
\text { Arrendamento } \\
\text { Mercantil }\end{array}$ & $\begin{array}{c}\text { IAS } 17 \\
\text { CPC } 06 \\
\text { Del. } 554 / 08\end{array}$ & $\begin{array}{l}\text { Institui a distinção entre leasing operacional e financeiro, requerendo que os } \\
\text { itens objeto de leasing financeiro sejam contabilizados como uma transação } \\
\text { de compra e venda mais financiamento. } \\
\text { Nas normas anteriores, todos os leasings eram contabilizados como um serviço } \\
\text { de aluguel, lançado no resultado quando incorrido (receita na arrendadora e } \\
\text { despesa na arrendatária). } \\
\text { Efeitos da caracterização de operações de leasing como financeiro: } \\
\text { Na arrendatária: contabilização como compra financiada, aumentando o Ativo } \\
\text { e o Passivo. A despesa com leasing é substituída pela depreciação do ativo } \\
\text { mais os juros. } \\
\text { Na arrendadora: contabilização como venda financiada, substituindo o } \\
\text { Imobilizado por Valores a Receber. O resultado da venda afeta o lucro no } \\
\text { momento da venda. Durante o prazo do contrato são reconhecidos apenas os } \\
\text { juros. }\end{array}$ \\
\hline $\begin{array}{l}\text { Subvenções e } \\
\text { Assistências } \\
\text { Governamentais }\end{array}$ & $\begin{array}{c}\text { IAS } 20 \\
\text { CPC } 07 \\
\text { Del. 555/08 }\end{array}$ & $\begin{array}{l}\text { Antes: subvenções e assistências governamentais reconhecidas diretamente } \\
\text { no patrimônio líquido como Reservas de Capital. } \\
\text { Agora: reconhecimento como receita no período em que forem cumpridas } \\
\text { todas as obrigações exigidas para que o benefício seja plenamente usufruído } \\
\text { (imediatamente ou ao longo do tempo). }\end{array}$ \\
\hline
\end{tabular}


Continuação do quadro 1.

\begin{tabular}{|c|c|c|}
\hline $\begin{array}{l}\text { Custos de } \\
\text { Transação e } \\
\text { Prêmios na } \\
\text { Emissão de } \\
\text { Títulos }\end{array}$ & $\begin{array}{l}\text { IAS 39 } \\
\text { (partes) } \\
\text { CPC 08 } \\
\text { Del. 556/08 }\end{array}$ & $\begin{array}{l}\text { Custos de transação na emissão de títulos: eram lançados no resultado no ato da } \\
\text { emissão. } \\
\text { Agora: (i) Títulos patrimoniais: os custos de transação na sua emissão são lançados } \\
\text { como conta redutora no Patrimônio Líquido, e não mais como redução do resultado } \\
\text { do período. (ii) Títulos de dívida: são contabilizados na emissão pelo valor líquido } \\
\text { disponibilizado pela transação. Assim, os custos de transação, prêmios e outros } \\
\text { são lançados no resultado ao longo do prazo da operação pela apropriação da taxa } \\
\text { de juros efetiva. } \\
\text { Prêmios na emissão de debêntures: antes lançados diretamente no Patrimônio } \\
\text { Líquido como Reserva de Capital; agora passam a ser tratados como receita. } \\
\text { Ambas as mudanças tendem a gerar aumento nos resultados das empresas no } \\
\text { exercício em que ocorrerem emissões. }\end{array}$ \\
\hline $\begin{array}{l}\text { Pagamentos } \\
\text { baseados em } \\
\text { ações }\end{array}$ & $\begin{array}{l}\text { IFRS } 2 \\
\text { CPC } 10 \\
\text { Del. CVM } \\
562 / 08\end{array}$ & $\begin{array}{l}\text { Institui o reconhecimento como despesa ou participações nas remunerações } \\
\text { baseadas em ações liquidadas com instrumentos patrimoniais (ações ou opções } \\
\text { de compra de ações), mensuradas pelo valor justo, no momento em que são } \\
\text { outorgados, em contrapartida da conta Ações/Opções Outorgadas, no Patrimônio } \\
\text { Líquido. } \\
\text { Antes, a remuneração baseada em ações só era reconhecida no resultado quando } \\
\text { a opção fosse exercida. }\end{array}$ \\
\hline $\begin{array}{l}\text { Ajuste } \\
\text { a Valor } \\
\text { Presente }\end{array}$ & $\begin{array}{l}- \\
\text { CPC } 12 \\
\text { Del. 564/08 }\end{array}$ & $\begin{array}{l}\text { Institui a exigência de se fazerem ajustes a valor presente de elementos integrantes } \\
\text { do ativo e passivo decorrentes de operações de longo prazo, ou de curto prazo, } \\
\text { quando houver efeitos relevantes. } \\
\text { O ajuste a valor presente deve ser efetuado na data de origem da transação, } \\
\text { utilizando-se a taxa contratual ou implícita. Na constituição, o ajuste pode ter } \\
\text { como contrapartida um ativo, despesa ou receita; as reversões terão contrapartida } \\
\text { em receita ou despesa (em geral) financeira. } \\
\text { Não há norma equivalente em IFRS, mas o princípio do valor presente aparece no } \\
\text { IAS 39, quando determina o valor justo, e no IAS } 37 \text {. } \\
\text { A mudança permite evidenciar o efeito no resultado dos juros implícitos em } \\
\text { operações comerciais a prazo, bastante comuns no mercado brasileiro, que tem há } \\
\text { décadas uma das maiores taxas de juros do mundo. }\end{array}$ \\
\hline $\begin{array}{l}\text { Instrumentos } \\
\text { Financeiros } \\
\text { (Fase 1) }\end{array}$ & $\begin{array}{l}\text { IAS 32/ } 39 \\
\text { (partes) } \\
\text { CPC 14 } \\
\text { Del. 566/08 }\end{array}$ & $\begin{array}{l}\text { Requer o reconhecimento e mensuração pelo valor justo de certos instrumentos } \\
\text { financeiros e derivativos, antes reconhecidos pelo custo amortizado e usando a } \\
\text { taxa nominal: } \\
\text { 1. Mantidos para Negociação: mensurados ao valor justo por meio do resultado. } \\
\text { 2. Disponíveis para Venda: diferenças entre o valor justo e o valor contábil } \\
\text { lançadas na conta Ajuste de Avaliação Patrimonial, no Patrimônio Líquido. } \\
\text { 3. Mantidos até o Vencimento: avaliados ao custo amortizado, mas com juros } \\
\text { calculados pela taxa efetiva. }\end{array}$ \\
\hline $\begin{array}{l}\text { Equivalência } \\
\text { Patrimonial }\end{array}$ & $\begin{array}{l}\text { IAS } 28 \\
\text { I n s t r } \\
469 / 08\end{array}$ & $\begin{array}{l}\text { Muda o conceito de coligada e, ao eliminar o teste de relevância dos investimentos, } \\
\text { amplia o alcance da aplicação do método de equivalência patrimonial, com efeito } \\
\text { no resultado. }\end{array}$ \\
\hline $\begin{array}{l}\text { Proibição da } \\
\text { Reavaliação } \\
\text { de Ativos }\end{array}$ & $\begin{array}{l}\text { IAS } 16 \text { e } 38 \\
\mathrm{~L} \quad \mathrm{e} \\
11.638 / 07 \\
\text { CPC } 13\end{array}$ & $\begin{array}{l}\text { Pró́be a reavaliação de ativos, antes permitida para o ativo imobilizado, } \\
\text { contrariando as IASs } 16 \text { e } 38 \text {. Ao proibir a reavaliação, a própria lei que } \\
\text { determinou a convergência para o IFRS instituiu uma diferença em relação ao } \\
\text { padrão internacional antes inexistente no Brasil. } \\
\text { As reavaliações efetuadas no passado podem, ou ser imediatamente revertidas, } \\
\text { ou mantidas e depreciadas normalmente, até que o ativo reavaliado se extinga ou } \\
\text { seja vendido. }\end{array}$ \\
\hline
\end{tabular}

Fonte: adaptado de Santos e Calixto (2010, p. 7ss). 


\section{METODOLOGIA}

Foram coletadas todas as DFPs de 2008 das empresas listadas na Bovespa disponibilizadas até 10/04/2009, exceto instituições financeiras (que apresentam características e regulação específicas), totalizando 318 empresas. Na sequência, foram examinadas todas as Notas Explicativas com o objetivo de coletar a tabela de reconciliação do efeito da nova lei no Lucro e PL, cuja apresentação foi determinada pelo CPC 13 na "adoção inicial" da lei $11.638 / 07$.

Algumas empresas apresentaram a tabela de reconciliação do efeito da nova lei apenas para o exercício de 2007, outras o fizeram apenas para 2008, e muito poucas o fizeram para os dois exercícios. Assim, optou-se por analisar todas as empresas com dados disponibilizados para pelo menos um dos exercícios (2007 e/ou 2008). Após exclusão de inconsistências, sobraram 175 empresas (55\% do total): para 2007, 84 empresas com informações sobre o efeito da lei no lucro e 114 no PL e, para 2008, 130 com reconciliação do lucro e 110 do PL.

Os ajustes reportados pelas empresas nas tabelas de reconciliação foram classificados nas onze categorias apontadas na Figura 1 e analisadas neste estudo. Foram adicionadas mais duas categorias, uma para os "efeitos tributários dos ajustes", quando reportados separadamente pelas empresas, e outra para abrigar os casos em que não foi possível classificar o ajuste em nenhuma das onze categorias definidas, denominada "outros efeitos".

Para mensurar o impacto de cada nova norma nos resultados foi utilizado o inverso do Índice de Comparabilidade Parcial de Weetman et al. (1998), derivado do Índice de Comparabilidade total, conforme a fórmula (2A) a seguir.

$$
\begin{gathered}
I C^{-1}=I C I=1-\left[\frac{\text { Resultado }_{\text {Lei } 6.404}-\text { Resultado }_{\text {Lei } 11.638}}{\mid \text { Resultado }_{\text {Lei } 6.404} \mid}\right]=1+\left[\frac{\text { Resultado }_{\text {Lei } 11.638}-\text { Resultado }_{\text {Lei } 6.404}}{\mid \text { Resultado }_{\text {Lei } 6.404} \mid}\right] \\
I C P^{-1}=I C P I=1+\left[\frac{\text { Ajuste Parcial }}{\mid \text { Resultado }_{\text {Lei } 6.404} \mid}\right](2 \mathrm{~A})
\end{gathered}
$$

Onde:

$$
\begin{aligned}
& I C^{-1}=I C I=\text { Índice de Comparabilidade Inverso } \\
& I C P^{-1}=I C P I=\text { Índice de Comparabilidade Parcial Inverso } \\
& \text { Resultado }{ }_{\text {Lei.6.404 }}=\text { Lucro Líquido/ prejuizo ou Patrimônio Líquido apurado conforme as normas } \\
& \text { vigentes até } 2007 \text { (Lei } 6.404 / 76 \text { e respectivas normas da CVM) } \\
& \text { Resultado }{ }_{\text {Lei.11.638 }}=\text { Lucro Líquido / prejuízo ou Patrimônio Líquido apurado conforme as normas } \\
& \text { vigentes a partir de } 2008 \text { (Lei } 11.638 / 07 \text { e CPCs } 1 \text { a 14) }
\end{aligned}
$$


Ajuste Parcial = cada ajuste por diferença normativa efetuado para reconciliar o Lucro Líquido / Prejuízo ou Patrimônio Líquido apurado conforme as normas anteriores com o apurado sob as novas normas

A utilização do inverso dos índices das equações (1) e (1A) anteriores, tomando como base a norma antiga, torna a análise mais intuitiva (valores maiores que 1 indicam aumentos e vice-versa).

Tratando-se neste estudo de uma abordagem censitária, a análise utiliza métricas de estatística descritiva. Entretanto, como referência para uma possível extrapolação dos resultados da pesquisa para além das empresas que reportaram determinado ajuste, foram também realizados testes de significância de média ( $t$-Student) e de mediana (teste de sinais por postos de Wilcoxon) para cada ajuste.

\section{RESULTADOS DA PESQUISA}

Os resultados desta pesquisa estão organizados em três partes: (1) análise dos ajustes que geraram aumento no lucro das empresas nos dois exercícios analisados; (2) análise dos ajustes que geraram queda no lucro das empresas nos dois exercícios; e (3) análise dos ajustes que ora geraram aumento, ora queda no lucro das empresas.

\subsection{Análise do impacto dos ajustes que geraram aumento no lucro das empresas}

\subsubsection{Custos de transação e prêmios na emissão de títulos}

As métricas gerais e distribuição de frequência do impacto das mudanças normativas que geraram aumento no lucro das empresas estão apresentadas na Tabela 1. Pela Tabela 1, o novo tratamento dos custos de transação e prêmios na emissão de títulos foi o ajuste que mais aumentou o lucro de 2007, quase triplicando (média do ICPI =2,92) o resultado das empresas que o reportam nesse exercício, e gerando um aumento médio de 15\% no lucro de 2008.

Esse grande aumento no lucro decorreria da mudança no tratamento dos custos de transação na emissão de ações, notadamente nas aberturas de capital (IPOs), antes tratados como despesa no momento em que eram incorridos, e agora como redução do valor captado. Com isso, encerrou-se de vez uma discussão aberta por algumas empresas, como a Gol, que à época pretendiam lançar seus gastos com IPO no Ativo Diferido, para evitar ter que lançálos contra o resultado, e ter que lidar com vultosas reduções no seu lucro no exercício em que abriam seu capital (ver ADASHI, 2005).

Uma possível explicação para a diferença na magnitude do ajuste entre os dois anos estaria na queda acentuada do número de emissões em 2008 em função da crise financeira global. Conforme dados da Bovespa, houve uma queda de $84 \%$ no número de emissões de ações em 2008 e de $51 \%$ no volume captado.

Além disso, o reconhecimento dos prêmios na emissão de debêntures como receita e 
não mais como Reserva de Capital também teria contribuído para um aumento no lucro.

Já a pequena redução nos resultados reportada por algumas empresas seria proveniente do novo tratamento dos custos de transação na emissão de títulos de dívida. Pela nova norma os títulos de dívida são contabilizados na emissão pelo valor líquido captado e os custos de transação, antes lançados como despesa no momento da emissão, agora são diluídos ao longo do prazo da operação pela apropriação da taxa de juros efetiva.

$\mathrm{O} \mathrm{ICPI}_{\mathrm{LL}}$ de 10,07 em 2007 foi apurado na Agra. De fato, o valor de R \$ 42,81 milhões, reportado para este ajuste, é quase igual a todo o lucro (R\$ 47,77 milhões) apurado no ano seguinte. Também foram apurados ICPIs da ordem de 5,5 na CR2 e OGX, mas esses foram afetados pelo baixo lucro reportado por essas empresas naquele ano.

\subsubsection{Subvenções governamentais}

Também gerou aumentos significativos no lucro das empresas a mudança do tratamento das subvenções governamentais, antes reconhecidas como Reserva de Capital no PL e, agora, como receita, no período em que forem cumpridas todas as obrigações exigidas para que o benefício seja plenamente usufruído.

Com isso, o desempenho econômico real de empresas que recebem benefícios governamentais é melhor expresso. Como notam Iudícibus et al. (2009, p. 40), esse novo tratamento "faz com que sejam devidamente evidenciados, na Demonstração do Resultado, a todos os leitores, que há um resultado incentivado a compor o desempenho da empresa".

De fato, os resultados apresentados na Tabela 1 mostram que esses incentivos são uma componente bastante relevante do desempenho dessas empresas, gerando um aumento médio de $24 \%$ no lucro das empresas que o reportaram em 2007 e de $21 \%$ em 2008, ambos estatisticamente signicativos a $10 \%$.

Os resultados de 2007 foram puxados pela Grendene e Alpargatas (ICPIs de 2,11 e 1,71 , respectivamente) e os de 2008 pela M. Dias Branco e novamente Grendene (ICPI $I_{L L}$ de 2,38 e 1,98), evidenciando o impacto desses incentivos no setor têxtil e em empresas do Nordeste. Note-se que esses incentivos geraram aumento de $10 \%$ ou mais no lucro de $48 \%$ das empresas que o reportaram em 2008 e de $36 \%$ em 2007. 


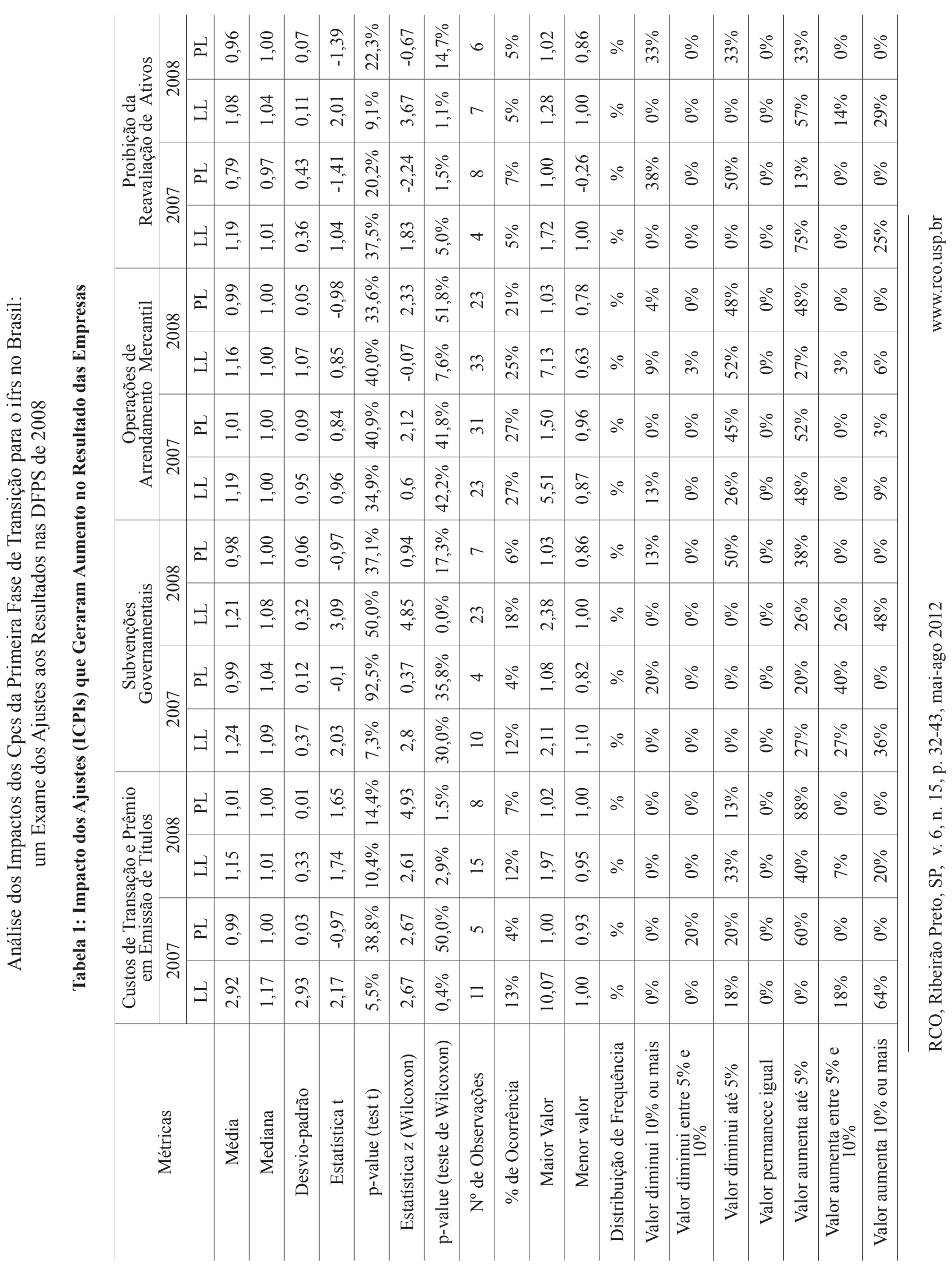


Pode-se também constatar que a ocorrência de subvenções governamentais não é desprezível: $18 \%$ das empresas que apresentaram a tabela de reconciliação dos resultados em 2008 efetuaram este ajuste no lucro.

\subsubsection{Operações de arrendamento mercantil (leasing)}

O novo tratamento do leasing financeiro constitui "uma espécie de corolário da primazia da essência sobre a forma" (IUDÍCIBUS et al., 2009, p.66). Antes, todas as operações de leasing eram tratadas como aluguel, e as contraprestações eram lançadas como despesa na arrendatária e receita na arrendadora. Mas, na realidade, muitas operações de leasing se caracterizam na essência como uma compra financiada, o que é reconhecido no novo padrão.

Duas razões principais explicariam a disseminação da prática de leasing financeiro ao invés do financiamento normal. Uma primeira seria possibilitar às empresas a manutenção de "passivos fora do balanço", seja por se acreditar que isso diminuiria o custo de captação de novos empréstimos, seja para evitar violar cláusulas restritivas a aumentos no endividamento, previstas em contratos de dívidas anteriores (STICKNEY e WEIL, 2007, p.472). Outra razão comum seria utilizá-lo como mecanismo de planejamento tributário.

Como mostra a Tabela 1, essa nova norma teve uma abrangência expressiva: seu ajuste no lucro foi reportado por $27 \%$ das empresas que apresentaram a tabela de reconciliação para 2007 e $25 \%$ para 2008 . Nota-se um aumento médio de $19 \%$ no lucro de 2007 e de $16 \%$ no de 2008, embora nem as médias nem as medianas tenham sido estatisticamente significativas.

De fato, a distribuição de frequência mostra grande discrepância no impacto desse ajuste entre as empresas: em 2007 aumentou o lucro de 57\% das empresas e, em 2008, reduziu o lucro de $64 \%$ delas.

Mas, na grande maioria das empresas, os impactos não foram tão significativos, permanecendo em torno de $5 \%$ para mais ou para menos em $74 \%$ das empresas em 2007 , e em $79 \%$ em 2008 .

Exceção se faz às companhias aéreas, que tinham grande parte de seus aviões obtidos por leasing financeiro. Na TAM, essa mudança multiplicou por 5,5 seu lucro e aumentou em $50 \%$ seu PL de 2007 (não foi reportada a tabela de reconciliação para 2008). Na Gol, o efeito foi o inverso: a mudança gerou uma redução de $32 \%$ no lucro e de $22 \%$ no PL de 2008 (não foi reportada a tabela de reconciliação para 2007). Vale ressaltar, embora em escala inferior, as empresas de logística: a ALL reportou uma queda de aproximadamente $10 \%$ no lucro dos dois anos e a Tegma teve um aumento da ordem de 12\% no lucro de 2008 (não foi reportada a tabela de reconciliação para 2007). O ICPI máximo de 7,13 no lucro de 2008 ocorreu na Marfrig, que teve seus efeitos distorcidos pelo baixíssimo resultado (prejuízo) reportado no ano.

Essa disparidade no impacto entre as empresas pode estar relacionada à idade dos ativos arrendados no momento da transição para as novas normas: ao substituir as despesas lineares de aluguel pela depreciação mais juros, dentro do conceito de juros compostos, o novo tratamento tende a gerar despesas maiores no início da vida útil dos ativos transacionados e menores no final. 
Análise dos Impactos dos CPC's da Primeira Fase de Transição para o IFRS no Brasil: um Exame dos Ajustes aos Resultados nas DFPS de 2008

\subsubsection{Proibição da reavaliação de ativos}

Sabe-se que nos períodos de alta inflação, a reavaliação do imobilizado era praticada no Brasil como antídoto à sua defasagem de valor, diante da aplicação de índices de correção monetária pouco realistas, definidos pelo governo como instrumento de política monetária. O problema é que essa prática gerou abusos, e não raras vezes foram reportadas reavaliações infladas, o que teria motivado, num primeiro momento, a determinação de condições para limitar sua prática por parte da CVM e, finalmente, sua completa proibição pela Lei 11.638/07.

Como mostra a Tabela 1, o estorno da depreciação a maior, decorrente da reavaliação do imobilizado, gerou um aumento médio de $19 \%$ no lucro das empresas que o reportaram em 2007 e de 8\% em 2008. A baixa dos saldos anteriores da Reserva de Reavaliação gerou uma redução média de $21 \%$ no PL de 2007 e de $4 \%$ no de 2008 , tendo sido o ajuste que mais impactou o PL das empresas. Surpreendentemente, em 2007, 8 empresas excluíram a Reserva de Reavaliação do PL, mas apenas 4 eliminaram do resultado o efeito da reavaliação na depreciação, o que indicaria uma inconsistência no lançamento desse ajuste.

Pela Tabela, poucas empresas (em torno de 5\%) reportaram esse ajuste. No entanto, isso não deve ser atribuído a uma baixa ocorrência da prática de reavaliação, mas à faculdade dada às empresas de não estornar os saldos remanescentes das reservas na data de transição, deixando-os reduzir gradativamente, mediante depreciação ou outras formas de redução, até sua extinção. De fato, verifica-se que 31\% das empresas disponíveis no banco de dados Economática tinham saldo na conta Reserva de Reavaliação em 2006, e 64\% delas ainda o mantiveram em 2008. Ou seja, quase $1 / 3$ das empresas abertas praticavam a reavaliação, mas apenas 36\% delas decidiram reverter totalmente seus saldos na data de transição.

Pode-se levantar a questão sobre até que ponto a proibição da reavaliação do imobilizado constitui uma real melhoria na qualidade da contabilidade brasileira.

Em primeiro lugar, ao eliminar a possibilidade de reavaliação, a lei 11.638/07 contradiz sua própria determinação de harmonização com o padrão internacional, já que esta é permitida no IAS 6. Para o bom êxito da harmonização contábil internacional, qual seria o limite de "customização" das IFRSs quando da sua adoção local por cada país?

Além disso, seria a proibição da reavaliação a ação mais eficaz para evitar eventuais abusos praticados por algumas empresas? Não seria preferível identificar e punir esses abusos para que eles não se repetissem? Com isso, certamente seria preservada a prática desse instrumento nos casos em que ele gerasse informações contábeis mais próximas da realidade econômica das empresas. Além disso, caso fosse mais conveniente para um usuário específico manter os ativos na base de custo, sempre haveria a possibilidade de se excluir o efeito da reavaliação, simplesmente estornando o saldo da reserva de reavaliação contra o valor do imobilizado, e somando ao resultado a parte da reserva realizada na forma de depreciação (diferença entre os saldos da Reserva de Reavaliação de dois exercícios).

Poder-se-ia ainda perguntar se a limitação da faculdade de julgamento da empresa sobre o valor justo de seu imobilizado, decorrente da proibição da reavaliação (mesmo justificável pelos abusos ocorridos), seria consistente com a abertura de tantos outros espaços para o julgamento, dentro do princípio de "subjetivismo responsável" inerente ao padrão IFRS.

Cabe ressaltar que uma determinada forma de reavaliação, sob a forma de "custo atribuído" (deemed cost), será permitida, uma única vez, ao se iniciar a depreciação pela vida útil econômica dos ativos na adoção do full IFRS em 2010 (CPC 37). Ora, essa prática, que se 
insere no princípio de melhor expressão da realidade econômica dos ativos, pareceria menos útil se, ao longo do tempo, alguns desses ativos, sem poderem ser reavaliados, se distanciarem inexoravelmente de sua realidade econômica.

\subsection{Análise do impacto dos ajustes que geraram queda no lucro das empresas}

\subsubsection{Redução de ativos ao seu valor recuperável (impairment)}

As estatísticas gerais do impacto das mudanças normativas que reduziram o lucro das empresas estão apresentadas na Tabela 2. As inquietações do mercado em torno da instituição do impairment no Brasil não parecem ter se materializado entre as empresas, pelo menos no ano de sua implantação. Esse ajuste foi reportado por apenas 8 empresas em 2008, tendo gerado queda média de $264 \%$ no lucro das empresas que o reportaram.

Exceto pela queda de mais de 20 vezes no lucro da Invest Tur, que distorceu a média do impacto, foram afetadas por esse ajuste a Tenda, com perda de 30\% do lucro, seguida pela Eletrobrás, Bradespar e Vale, com perdas da ordem de 10\%. Impairment também foi reportado pela Braskem, Copasa e Minerva, mas seu efeito ficou em perdas de apenas $1 \%$ nas duas primeiras e $3 \%$ na última.

\subsubsection{Extinção da Capitalização de Despesas}

As novas normas extinguiram a prática de ativação de gastos durante o período de desenvolvimento e implantação de projetos que beneficiem exercícios futuros, amortizandoos nos períodos em que seus benefícios fossem auferidos. Com isso, afora os intangívis adquiridos, são atualmente capitalizáveis apenas os intangíveis desenvolvidos internamente em que se possa distinguir a fase de "pesquisa" da de "desenvolvimento" e que atendam todos os requisitos expressos nos itens 51 a 66 do CPC 04.

A lógica da extinção do diferimento de despesas, segundo Iudícibus et al.(2009, p.32), estaria na "quase impossibilidade prática de efetiva confrontação desses gastos transformados em despesas com as receitas a que se vinculam", resultando em uma amortização arbitrária.

Críticos a essa mudança tendem a alegar prejuízo do princípio da confrontação entre receitas e despesas, com aumento exagerado do conservadorismo na mensuração de ativos e resultados, e possível afastamento do seu valor econômico real. No entanto, seu benefício imediato estaria na sensível redução do espaço antes existente para práticas questionáveis de gerenciamento de resultados via capitalização de despesas de modo impróprio.

Conforme a Tabela 2, a capitalização de despesas era largamente praticada: $43 \%$ das empresas que apresentaram a tabela de reconciliação para o lucro de 2007 efetuaram esse ajuste. Sua extinção impactou significativamente o resultado das empresas, gerando uma queda média da ordem de $40 \%$ nos resultados de 2007 e de $130 \%$ nos resultados de 2008 (ICPI $=-0,31)$, embora esta última não tenha sido estatisticamente significativa, dada a distorção causada pelo ICPI de -45,91 apurado na Pronor. Se excluído, o ICPI médio passa a 0,92 e o p-value a $0,2 \%$. Note-se, pela distribuição de frequência, que $1 / 3$ das empresas que registraram este ajuste tiveram queda acentuada ( $10 \%$ ou mais) nos resultados dos dois anos. 


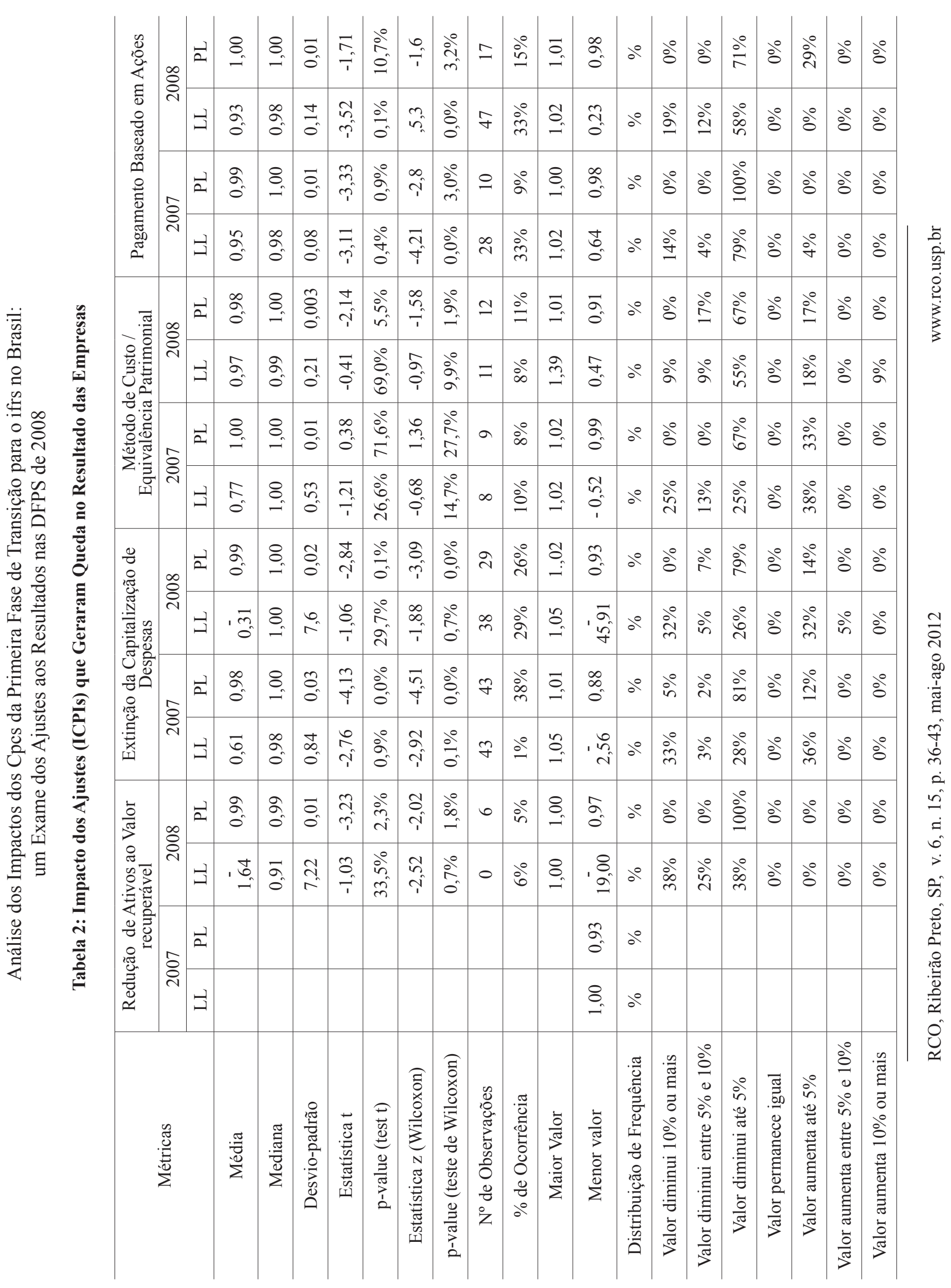


O impacto da mudança foi especialmente sentido nas empresas do setor de construção, que tinham como prática capitalizar gastos com propaganda para lançamento de novos prédios no estoque (custo de construção do imóvel) e agora terão que lançá-los diretamente contra o resultado no momento em que ocorrerem, seguindo orientação específica da OCPC 01. Com isso, o resultado das empresas do setor que reportaram esse ajuste caiu em média $113 \% \mathrm{em}$ 2007 e $17 \%$ em 2008.

No entanto, no longo prazo, prevê-se uma equalização do resultado para os casos de gastos com pesquisa, propaganda e treinamento, se a empresa tiver como política manter uma "verba" constante para esses gastos, como uma espécie de "investimento contínuo" na expectativa de colher benefícios no futuro. Isso tende a acontecer também nas empresas de construção que mantiverem uma taxa constante de lançamento de novos prédios. Já para os casos de despesas esporádicas de valores significativos, como os gastos pré-operacionais, com implantação de sistemas e reestruturação, prevêem-se oscilaçoes nos resultados das empresas nos exercícios em que ocorrerem, já que seus efeitos não poderão mais ser diluídos nos resultados de vários períodos. Note-se que ainda poder-se-á encontrar o Diferido no balanço das empresas, uma vez que a baixa imediata dos saldos anteriores não foi obrigatória. A partir do banco de dados da Economática verifica-se que, dentre as empresas que tinham saldo no Diferido no exercício de 2006, 40\% não o baixaram até o exercício de 2008. Para elas, prevêse um aumento no valor das despesas nos próximos anos, pois, além das novas despesas incorridas no período (antes passíveis de capitalização), terão que ser lançadas as amortizações de períodos anteriores até que seus saldos sejam completamente eliminados.

\subsubsection{Aumento da exigência de aplicação do método de equivalência patrimonial}

A mudança na aplicação do método de equivalência patrimonial parece ter afetado poucas empresas (cerca de 10\%), tendo gerado efeitos bastante divergentes (queda média de $23 \%$ em 2007, mas de apenas $3 \%$ em 2008, e média e mediana não são estatisticamente significativas). Por outro lado, a grande ocorrência de diminuições nos resultados (em pelo menos $2 / 3$ das empresas nos dois anos) indica que a extensão da aplicação do método de equivalência patrimonial (com a extinção do teste de relevância do investimento e o novo conceito de influência significativa) aumentou a transparência dos resultados de investimentos em outras companhias, revelando prejuízos em investimentos antes não reportados.

\subsubsection{Pagamentos baseados em ações}

O ajuste pela mensuração de pagamentos baseados em ações pelo seu valor justo, com variações reconhecidas no resultado do período em que ocorrerem, foi reportado por $1 / 3$ das empresas e gerou uma redução média de 5\% no lucro de 2007 e de $7 \%$ em 2008. Confirma-se a expectativa de que esses instrumentos não pesariam muito no resultado das empresas, já que normalmente são reservados à remuneração de poucos altos executivos.

\subsection{Análise do impacto dos ajustes que ora aumentaram, ora reduziram o lucro das empresas}

As estatísticas gerais do impacto dos ajustes que ora aumentaram, ora reduziram o lucro das empresas estão apresentadas na Tabela 3. 
Análise dos Impactos dos CPC's da Primeira Fase de Transição para o IFRS no Brasil: 38 um Exame dos Ajustes aos Resultados nas DFPS de 2008

\begin{tabular}{|c|c|c|c|c|c|c|c|c|c|c|c|c|c|c|c|c|c|c|c|c|c|}
\hline \multirow{4}{*}{\multicolumn{2}{|c|}{ 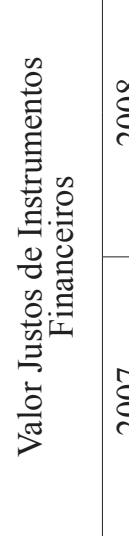 }} & $\vec{a}$ & ô. & $\stackrel{8}{-}$ & $\frac{m}{0}$ & $\begin{array}{c}\infty \\
\rightarrow \\
-\end{array}$ & ڤ̆ & 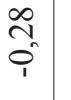 & $\begin{array}{l}\stackrel{0}{\circ} \\
\stackrel{0}{\circ}\end{array}$ & 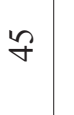 & $\frac{\circ}{\sigma}$ & $\stackrel{8}{-}$ & $\frac{\infty}{0}$ & \multicolumn{2}{|c|}{ 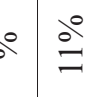 } & $\stackrel{+}{\circ}$ & ڤे & \multicolumn{2}{|l|}{ ठे } & $\stackrel{\circ}{~}$ & ठे \\
\hline & & ב & $\hat{\sigma}$ & 8 & $\frac{n}{2}$ & $\begin{array}{l}\hat{\lambda} \\
\hat{i}\end{array}$ & $\begin{array}{l}8^{\circ} \\
a^{\circ}\end{array}$ & $\stackrel{I}{0}$ & $\begin{array}{l}b_{0}^{\circ} \\
\text { do }\end{array}$ & in & $\stackrel{\stackrel{\circ}{\sigma}}{\forall}$ & 点 & ले & $a^{\circ}$ & ڤ̊ & ஓें & 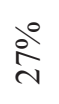 & ठ̊ & $\stackrel{\stackrel{\circ}{~}}{\circ}$ & ठ̊ & $\stackrel{\stackrel{\partial}{ \pm}}{-}$ \\
\hline & & $\vec{a}$ & $\tau$ & 8 & $\begin{array}{l}\text { ô. } \\
\text { o. }\end{array}$ & $\hat{\alpha}$ & $\begin{array}{l}8^{\circ} \\
\dot{m} \\
\dot{m}\end{array}$ & $\begin{array}{l}0 \\
: \\
i\end{array}$ & 离 & \% & ळें & $\stackrel{0}{=}$ & g. & $0^{\circ}$ & ठें & $\stackrel{\circ}{\circ}$ & $\frac{\partial^{\circ}}{n}$ & $8^{\circ}$ & $\stackrel{\circ}{\dot{y}}$ & ेํํ & 8̊ \\
\hline & & コ & $\stackrel{0}{0}$ & $\stackrel{8}{-}$ & $\frac{1}{0}$ & $\hat{a}$ & $\begin{array}{l}\text { बें } \\
\text { ले }\end{array}$ & $\begin{array}{l}8 \\
0 \\
1\end{array}$ & 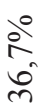 & $m$ & ळे & $\stackrel{n}{\approx}$ & $\begin{array}{l}\text { t. } \\
\text { oे }\end{array}$ & $\partial^{\circ}$ & ठ̊ & ஓें & 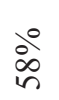 & ठ̊ & ठ̊ํㄹ & लें & bे \\
\hline & & $\vec{a}$ & $\underset{0}{0}$ & $\stackrel{8}{-}$ & $\overbrace{0}^{0}$ & $\stackrel{\infty}{\sim}$ & $\begin{array}{c}\infty \\
\infty \\
\infty \\
\infty \\
\infty \\
0\end{array}$ & $\begin{array}{l}\infty \\
\stackrel{2}{\sigma} \\
\sigma^{\prime}\end{array}$ & $\begin{array}{c}\text { बें } \\
\text { लn } \\
\text { ñ }\end{array}$ & $\simeq$ & $\stackrel{\stackrel{\circ}{ \pm}}{=}$ & $\stackrel{\varrho}{\Rightarrow}$ & $\stackrel{\infty}{\circ}$ & $\partial^{\circ}$ & ठे & ठे & ले & ठ̊ & ठें & $\stackrel{0}{2}$ & ठ̊ \\
\hline 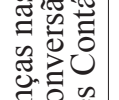 & e & $\exists$ & \begin{tabular}{l}
$\infty$ \\
\multirow{2}{*}{} \\
0
\end{tabular} & ถ̊ & $\stackrel{?}{\stackrel{n}{m}}$ & $\frac{\Delta}{i}$ & $\begin{array}{l}\text { in } \\
\text { in } \\
\text { in }\end{array}$ & $\stackrel{\vec{A}}{\vec{i}}$ & $\begin{array}{l}\delta_{0}^{\circ} \\
0 \\
0\end{array}$ & లి & ஸें & $\stackrel{+}{\sigma}$ & $\begin{array}{l}\tilde{\alpha} \\
\frac{1}{1}\end{array}$ & $\partial^{\circ}$ & 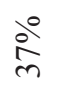 & $\stackrel{\circ}{0}$ & ஓें & ठे & $\stackrel{\circ}{2}$ & $\stackrel{\circ}{\circ}$ & ले \\
\hline 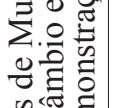 & & $\vec{a}$ & $\begin{array}{l}0 \\
\infty \\
0 \\
0\end{array}$ & $\begin{array}{l}\infty \\
\infty \\
0\end{array}$ & $\tilde{\sigma}$ & $T$ & $\begin{array}{l}8^{\circ} \\
0^{\circ} \\
\text { in }\end{array}$ & $\stackrel{8}{-}$ & $\begin{array}{l}80 \\
8 \\
0^{\circ}\end{array}$ & $\sim$ & ¿े & $\stackrel{8}{-}$ & $\vec{\sigma}$ & $a^{\circ}$ & 今ें & ठे & ठ̊ & ठे & 今ें & ठ̊ & ठ̊ \\
\hline$\sum_{4}^{\infty}$ & $\sim$ & $\exists$ & $\stackrel{0}{=}$ & $\overbrace{-}^{-}$ & $\frac{ \pm}{0}$ & $\stackrel{\infty}{\stackrel{\infty}{n}}$ & $\begin{array}{l}\dot{0}^{\circ} \\
0^{\circ}\end{array}$ & बे & $\frac{0^{\circ}}{0^{\circ}}$ & 2 & ஸें & $\stackrel{\text { g }}{\rightarrow}$ & हू & $\partial^{\circ}$ & ठ̊ & in & ठ̊ & ठ̊ & $\stackrel{\circ}{\infty}$ & ìं & ํํํ \\
\hline & & $\vec{a}$ & बे & $\stackrel{8}{-}$ & $\begin{array}{l}\overline{0} \\
\sigma_{0}\end{array}$ & $\stackrel{\infty}{\stackrel{p}{r}}$ & $\begin{array}{l}\text { तें } \\
\text { ô }\end{array}$ & $\begin{array}{c}0 \\
\infty \\
i \\
1\end{array}$ & $\frac{0^{\circ}}{0^{\circ}}$ & $\hat{n}$ & 文 & $\stackrel{0}{0}$ & $\tilde{a}$ & $\partial^{\circ}$ & ठें & ठे & $\stackrel{\stackrel{े}{ }}{\sim}$ & ठ̊ & dें & ठें & ठे \\
\hline 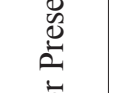 & & $\exists$ & $\stackrel{\text { o }}{-}$ & $\begin{array}{l}\text { ळे } \\
\text { oे }\end{array}$ & $\begin{array}{l}\tilde{F}_{0} \\
\stackrel{0}{*}\end{array}$ & 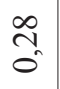 & 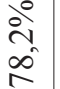 & $\begin{array}{l}\tilde{I} \\
\tilde{\imath}\end{array}$ & $\begin{array}{l}8^{\circ} \\
0 \\
0\end{array}$ & 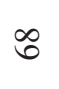 & iे & $\stackrel{\infty}{\stackrel{\infty}{*}}$ & $\begin{array}{l}\text { d } \\
0 \\
0\end{array}$ & $\partial^{\circ}$ & ఏ̊ర & ì & $\stackrel{\circ}{\infty}$ & ठ̊ & $\stackrel{\stackrel{\circ}{+}}{\sim}$ & $\stackrel{\circ}{\circ}$ & dे \\
\hline 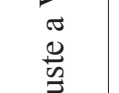 & & $\vec{a}$ & बे & 8 & $\begin{array}{l} \pm \\
0 \\
0\end{array}$ & $\stackrel{m}{\hat{i}}$ & 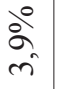 & $\begin{array}{l}\hat{n} \\
\hat{i}\end{array}$ & $\frac{\partial^{\circ}}{0^{\circ}}$ & F & $\begin{array}{l}\stackrel{0}{\infty} \\
\text { n }\end{array}$ & $\stackrel{+}{0}$ & $\frac{2}{0}$ & $\partial^{\circ}$ & in & ठे & ¿ें & ठे & ஷें & ठ̊ & ठे \\
\hline & & コ & $\begin{array}{l}\vec{\infty} \\
0\end{array}$ & $\begin{array}{l}\text { ूे } \\
\text { ठे }\end{array}$ & $\dot{\sigma}_{0}^{+}$ & $\hat{n}$ & å & $\stackrel{\substack{2 \\
i}}{i}$ & $\begin{array}{l}\text { خें } \\
\text { ते } \\
0\end{array}$ & $\widehat{\imath}$ & ஸे & $\underset{\sigma}{\sigma}$ & $\begin{array}{l}\vec{n} \\
\hat{1}\end{array}$ & $\partial^{0}$ & $\stackrel{\text { ले }}{\text { ले }}$ & ठे & $\stackrel{\text { ले }}{\text { ले }}$ & 8̊ & $\stackrel{\text { ले }}{\text { ले }}$ & ठ̊ & 8̊ \\
\hline & & & : & 㞼 & 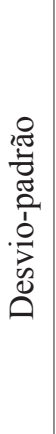 & 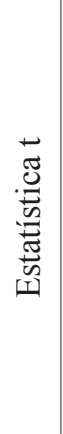 & 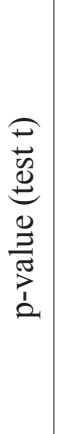 & 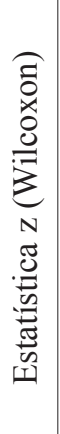 & 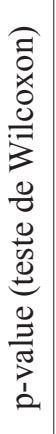 & 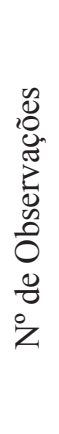 & $\begin{array}{l}\frac{\pi}{0} \\
0 \\
0 \\
0 \\
0 \\
0 \\
0 \\
0 \\
0 \\
0\end{array}$ & 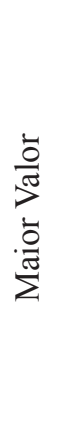 & 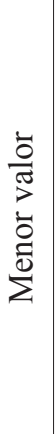 & 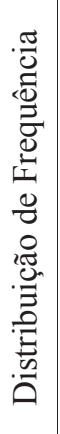 & 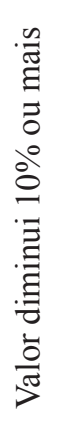 & 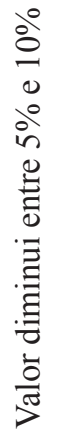 & 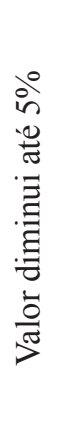 & 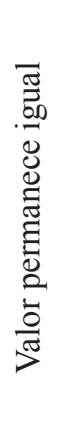 & 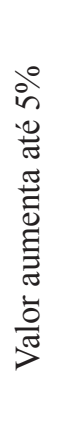 & 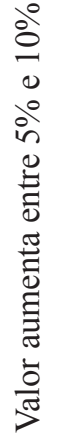 & 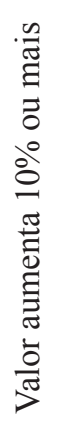 \\
\hline
\end{tabular}




\subsubsection{Ajuste a valor presente}

Conforme a Tabela 3, o Ajuste a Valor Presente foi bastante frequente, tendo sido efetuado por $52 \%$ das empresas que reportaram a tabela de reconciliação do resultado de 2008 e $32 \%$ das que o fizeram para 2007. O lucro cai em média $20 \%$ em 2007, mas fica praticamente inalterado em 2008, este distorcido pelos dados da Marfrig, que apontou um lucro 4,8 vezes maior em função desse ajuste. Se excluído, a queda média em 2008 passa para $-5 \%$, com $p$-value de $0,04 \%$. Novamente foram mais afetadas as empresas do setor de construção, reportando queda média de quase $40 \%$ no lucro de 2007 . Nota-se que esse ajuste gerou queda no lucro de pelo menos $2 / 3$ das empresas, indicando uma preponderância dos ajustes a valor presente de ativos sobre os de passivos.

Assim, verifica-se que o ajuste a valor presente de valores a pagar e a receber decorrente de operações comerciais a prazo mostrou-se prática importante para explicitar os juros praticados nessas operações, com valiosas contribuições para se distinguir, na análise financeira das empresas, custos e receitas genuinamente operacionais daqueles decorrentes do financiamento de operações comerciais.

\subsubsection{Efeitos de mudanças nas taxas de câmbio e conversão de Demonstrações Contábeis}

Pela Tabela 3, o impacto do ajuste de mudanças nas taxas de câmbio e conversão de demonstrações contábeis apresentou um comportamento um tanto heterogêneo, quer dentro de um mesmo exercício, quer entre períodos: em 2007 ocorreu um aumento médio de quase $10 \%$ no lucro das 19 empresas que reportaram esse ajuste e uma queda de quase $-15 \%$ no PL nas 2 empresas que o registratam; em 2008 ocorreu uma redução média de -72\% no lucro das 30 empresas que o reportaram, sem praticamente afetar o PL.

Essa disparidade de comportamento pode ser atribuída à confluência de dois fatores. A diferença de impacto do ajuste de um exercício para outro provavelmente se deve às grandes oscilações nas taxas de câmbio nesse período (o Dólar, por exemplo, teve uma queda de $17 \%$ em relação ao Real no exercício de 2007 e uma valorização de 32\% em 2008).

Já as grandes diferenças entre os impactos no LL e no PL estariam relacionadas à definição da moeda funcional da empresa, que determina se os ganhos ou perdas decorrentes da conversão das demonstrações contábeis serão reportados no resultado ou no PL. Na conversão para a moeda funcional os ganhos e perdas são reportados no resultado, e na conversão da moeda funcional para a moeda de relatório (no caso o Real), eles são reportados como ajuste no PL. Assim, se o Real for definido como moeda funcional, os ganhos e perdas na conversão de subsidiárias no exterior para o Real serão reportados no resultado. Caso a moeda funcional seja definida como o Dólar, como ocorreu, por exemplo, na Embraer, poderão existir duas conversões: de outra moeda estrangeira para o Dólar, com os ganhos e perdas reportados no resultado, e do Dólar para o Real, com os ganhos e perdas reportados no PL.

\subsubsection{Avaliação a valor justo de instrumentos financeiros}

Conforme a Tabela 3, a entrada em vigor da avaliação a valor justo de alguns instrumentos financeiros, com as diferenças lançadas no resultado, não trouxe impacto tão significativo no lucro das empresas. O efeito ficou limitado a aproximadamente $3 \%$ para mais 
ou para menos nos dois anos (note-se que as instituições financeiras não estão incluídas neste estudo).

Isso não parece decorrer da preferência pela classificação dos títulos como "disponíveis para venda", com vista ao registro dos seus efeitos diretamente no Patrimônio Líquido, pois este ajuste praticamente não impactou o PL em 2007, e gerou uma queda de apenas $3,5 \%$ em 2008.

De fato, a distribuição de frequência mostra que em 2007 o impacto desse ajuste no lucro girou em torno de 5\%, para mais ou para menos, em $88 \%$ das empresas (redução de até $5 \%$ no lucro em 58\% das empresas e aumento em 30\% delas). Já em 2008, em pleno auge da crise financeira, observam-se grandes variações em posições contrárias: enquanto $19 \%$ das empresas reportaram perdas de mais de $10 \%$ no lucro, $14 \%$ delas reportaram ganhos dessa mesma ordem.

Dentre as empresas mais impactadas por este ajuste destacam-se, além da Sadia, com perdas de $340 \%$ do seu LL e $82 \%$ do seu PL, a Hering e a Eluma, com perdas de mais de $55 \%$ do lucro. Dentre os maiores ganhos, destacam-se o de $250 \%$ da Rede Energia, o de $165 \%$ da Iguaçu, o de $100 \%$ da Dasa e o de $84 \%$ da BR Malls. Assim, em 2008 grandes efeitos negativos e positivos acabaram se contrabalançando e resultaram numa queda média pequena. Note-se que esse ajuste foi bastante frequente: em torno de $40 \%$ das empresas o reportaram nos dois exercícios.

\section{CONCLUSÃO}

Este trabalho procurou efetuar uma análise dos impactos de cada nova norma (CPCs 1 a 14) da primeira fase de transição da contabilidade brasileira para o IFRS nos resultados das empresas listadas na Bovespa, reportados nas DFPs de 2008.

O impacto de cada ajuste, mensurado pelo inverso do "Índice de Comparabilidade Parcial" de Weetman et al. (1998), foi analisado mediante estatística descritiva, tendo sido ainda realizados testes de média ( $t$-Studend) e de mediana (Wilcoxon).

Dentre as normas que geraram aumentos mais expressivos no lucro das empresas, destacaram-se: a exclusão dos custos de transação e prêmios na emissão de títulos da apuração do resultado, que em média triplicou o lucro de 2007 das empresas que o registraram; a inclusão dos incentivos fiscais no resultado, com aumento médio de $24 \%$ nos lucros de 2007 e de 21\% em 2008; e a inclusão do conceito de arrendamento mercantil financeiro e proibição da reavaliação de ativos, ambos com aumento médio de $19 \%$ no lucro de 2007 . Por outro lado, a redução ao valor recuperável de ativos provocaram quedas expressivas do lucro, reduzindo em média 260\% o lucro das empresas que o registraram em 2008, e a extinção da capitalização de despesas, com redução média de $130 \%$ nos lucros de 2008 e de $40 \%$ em 2007.

A análise dos efeitos de cada ajuste foi realizada dentro do princípio fundamental do julgamento sobre a melhor expressão da realidade econômica da empresa, com primazia da essência sobre a forma. Em pelo menos um caso - a proibição da reavaliação de ativos - a nova norma, ao coibir exageros de práticas anteriores, corre o risco de se afastar da representação do valor econômico real de ativos e resultados. Essa proibição atua em sentido expressamente contrário ao critério do IFRS, levantando a questão de o combate ao gerenciamento de resultados ser mais eficaz via uma proibição formal, na linha tradicional brasileira, ou via melhorias no monitoramento do julgamento contábil da realidade, na linha do padrão internacional. Tanto mais que outros itens das novas normas abrem oportunidades muito maiores para 
o gerenciamento de resultados, que demandarão tal controle pró-ativo do regulador.

Ao mensurar o impacto de cada nova norma da primeira fase de transição para o IFRS nos resultados das empresas, este trabalho pretende ter gerado contribuições para a prática da análise financeira, sobretudo de empresas e setores mais afetados pelas novas normas. Também espera ter contribuído com reflexões sobre as mudanças normativas, como evolução na qualidade da informação contábil para melhor representação da realidade econômica das empresas, dentro do objetivo do IFRS.

As várias limitações da presente investigação decorrem tanto das características das normas de transição, que facultaram às empresas diversas opções de seu cumprimento, como da inevitável diversidade do nível de assimilação das novas normas no primeiro ano de sua vigência. A consequente disparidade se expressa em discrepâncias acentuadas de comportamento estatístico em detrimento da acuidade desta pesquisa. Espera-se que tais dificuldades sejam atenuadas ao longo dos próximos períodos, em particular após a adoção do full IFRS a partir do exercício de 2010, em benefício de novas pesquisas sobre o tema.

\section{REFERÊNCIAS}

ADASHI, V. Gol poderá ter que republicar balanço. Jornal Valor Econômico, São Paulo, 16/12/2005. Disponível em http://www.valoronline.com.br/. Acesso em 16/12/2005.

BRASIL, Lei $n^{\circ} 11.638$ de 28/12/2007. Altera e revoga dispositivos da Lei 6.404/76. Disponível em http://www.cvm.gov.br/. Acesso em 10/01/2008.

BECKMAN, J.; BRANDES, C.; EIERLE, B. German reporting practices: an analysis of reconciliation from German commercial code to IFRS or US GAAP. Advances in International Accounting, v. 20, p. 253-294, 2007.

CORDAZZO, M. The impact of IAS/IFRS on accounting practices: evidence from Italian listed companies. In Séminaire DEMA/ERM, 2008. Disponível em http://www.hec.unil.ch/ irm/Research/Seminaire . Acesso em 14/05/2009.

CVM - Comissão de Valores Mobiliários. Instruções e Deliberações. Disponível em www. cvm.gov.br. Acesso em 15/08/2009.

CPC - Comitê de Pronunciamentos Contábeis. Pronunciamentos Técnicos. 2008. Disponível em www.cpc.com.br. Acesso em 15/08/2009.

DING Y.; JEANJEAN, T.; SOTOLOWY, H. Why do national GAAP differ from IAS? The role of culture. The International Journal of Accounting, v. 40, n. 4, p. 325-350, 2005.

DOUPNIK, T. S.; RICCIO, E. L. The influence of conservatism and secrecy on the interpretation of verbal probability expressions in the Anglo and Latin culture areas. The International Journal of Accounting, v. 41, n. 3, p. 237-261, 2006.

FURURUTA, F.; BISPO, J. S.; VIEIRA, P. S. Convergência internacional: nível de disclosure e impacto de inovações legais sobre o Patrimônio Líquido e o Resultado das grandes empresas instaladas no Brasil. In: Congresso USP de Controladoria e Contabilidade, $9^{\circ}$, Anais, FEAUSP, São Paulo, 2010.

GRAY, S. J. The impact of international accounting differences from a security analysis perspective: some european evidence. Journal of Accounting Research, v. 18, n.1, p. 64-76, 1980. 
.Towards a theory of cultural influence on the development of accounting systems internationally. Abacus, v. 24, n. 1, p.1-15, 1988.

GRECCO, M. C. P.; GERON, C. M. S.; FORMIGONI, H. O impacto das mudanças nas práticas contábeis no nível de conservadorismo das companhias abertas brasileiras. In: Congresso Brasileiro de Custos, XVI, Fortaleza. Anais... Fortaleza: UNIFOR, 2009.

IUDÍCIBUS, S.; MARTINS, E.; GELBCKE, E. R. Manual de contabilidade das sociedades por ações - Suplemento. $2^{\mathrm{a}}$ ed. São Paulo: Atlas, 2009.

LEMES, S., CARVALHO, L. N. G, OLIVEIRA-LOPES, L. C. Comparabilidade entre os BR GAAP e os US GAAP: algumas evidências das companhias brasileiras listadas na NYSE. In: ENANPAD, 31, Rio de Janeiro. Anais... Rio de Janeiro: ANPAD, 2007.

LIPPI, R. Mudança contábil exige novo perfil de profissionais. Jornal Valor Econômico, São Paulo, 03/04/2009.

NIERO, N. Novas regras prometem emoções fortes. Jornal Valor Econômico, São Paulo, $13 / 06 / 2008$.

NIERO N.; VALENTI, G.; D’AMBROSIO, D. Confusão contábil prejudica análise de balanços de 2008. Jornal Valor Econômico, São Paulo, 09/03/2009.

NIYAMA, J. K. Contabilidade Internacional. São Paulo: Atlas, 2005.

O'CONNELL, V.; SULLIVAN, K. The impact of mandatory conversion to IFRS on the net income of FTSEurofirst 80 firms. Journal of Applied Research in Accounting and Finance, v. 3 , n. 2, p. 17-26, 2008.

RADEBAUGH, L. H.; GRAY, S. J.; BLACK, E. L. International accounting and multinational enteprises. Hoboken: Wiley, 2006.

SANTOS, E. S., CALIXTO, L. Impactos do Início da Harmonização Contábil Internacional (Lei 11.638/07) nos Resultados das Empresas Abertas. RAE eletrônica, v. 9, n. 1, jan-jun, 2010 .

SANTOS, E. S., CIA, J. N. S., CIA, J. C. US GAAP x Normas Brasileiras: Há Diferenças Significativas no Valor do Lucro Reportado pelas Empresas Brasileiras com ADRs na NYSE? In: ENANPAD, 31, Rio de Janeiro. Anais... Rio de Janeiro: ANPAD, 2007.

SANTOS, E. S., CIA, J. N. S. Impactos esperados da harmonização internacional no lucro das empresas brasileiras, na proxy dos ajustes BRGAAP/USGAAP reportados pelas emissoras de ADRs na NYSE. Revista de Contabilidade e Organizações - RCO, vol 3, n. 6, p. 57-79, 2009.

SANTOS, E. S. Impactos do início da harmonização contábil internacional (Lei 11.638/07) nos resultados de 2008 das empresas brasileiras abertas. Relatório de Pesquisa do NPP/FGVEAESP, 2009. (extrato publicado em Santos e Calixto, 2010).

SAUDAGARAN, S. M. International Accounting: a user perspective. Mason: Thomson, 2001.

STICKNEY, C. P.; WEIL, R. L. Financial Accounting. 12 $2^{\text {nd }}$ ed. Mason: Thomson, 2007.

TORRES, F. Efeitos colaterais. Jornal Valor Econômico, São Paulo, 09/12/2009.

WEETMAN, P.; JONOES, E. A. E.; ADAMS, E. A.; GRAY, S. J. Profit measurement and UK accounting standards: a case of increasing disharmony in relation to US GAAP and IASs. Accounting and Business Research, v. 28, n. 3, p.189-208, 1998. 


\section{DADOS DO AUTOR:}

\section{EDILENE SANTANA SANTOS}

Escola de Administração - Fundação Getúlio Vargas

Av. 9 de Julho, 2029 - Bela Vista

São Paulo, SP - Brasil

01313-902 